\title{
ESTUDO DOS BIOMARCADORES RENAIS NA AVALIAÇÃO DO DANO: ESTUDO DE REVISÃO
}

\section{ARTIGO DE REVISÃO}

BORGES, Lysandro Pinto ${ }^{1}$

ALMEIDA, Larissa Oliveira de ${ }^{2}$

BORGES, Lysandro Pinto. ALMEIDA, Larissa Oliveira de. Estudo dos biomarcadores renais na avaliação do dano: Estudo de revisão. Revista Científica Multidisciplinar Núcleo do Conhecimento. Ano 04, Ed. 07, Vol. 04, pp. 05-19. Julho de 2019. ISSN: 2448-0959

\section{RESUMO}

Os biomarcadores renais são dispostos como ferramentas para um diagnóstico preciso e precoce evitando a progressão da patologia, e piores custos para o paciente, melhorando sua qualidade de vida. Os mais utilizados são marcadores da Taxa de Filtração Glomerular (TFG) endógenos e exógenos. A creatinina é o padrão laboratorial mais utilizado devido ao seu baixo custo e por ter diversos estudos que comprovam sua efetividade apesar de interferentes, é comum o seu uso em conjunto com a uréia para confirmar diagnóstico. A inulina e a cistatina $\mathrm{C}$ vem emergindo como potenciais substitutos para os mais antigos, como a creatinina, porém ainda se faz necessário estudos experimentais. $\mathrm{Na}$ avaliação da proteinúria, a albumina é a mais utilizada clinicamente. Outro marcador é apresentado pelos eritrócitos, quando estes sofrem alterações morfológicas ao passarem pelo aparelho renal lesado. Por fim, as moléculas KIM-1, IL-18 e NGAL são citadas como mais fidedignas ao diagnóstico de

${ }^{1}$ Doutor em Bioquímica Toxicológica, Mestre, Especialista em Análises Clínicas, Farmacêutico pela UFSM.

${ }^{2}$ Farmacêutica pela UFS. 
Insuficiência Renal Aguda (IRA). Este estudo revisa quais marcadores estão sendo mais estudados para a prática laboratorial, no auxílio do diagnóstico.

Palavras-chaves: nefropatias, patologia, efetividade, homeostase.

\section{INTRODUÇÃO}

Os rins são órgãos de fundamental importância para manutenção da homeostase. Estes órgãos possuem funções como excreção de subprodutos metabólicos, regulação do volume e composição hídrica, manutenção do equilíbrio ácido-básico e da pressão sanguínea, além de atuar como órgão endócrino. Alterações nas funções renais levam às chamadas nefropatias, como a Doença Renal Crônica (DRC) e Insuficiência Renal Aguda (IRA), que podem ser diagnosticadas laboratorialmente através de biomarcadores renais. ${ }^{1,2}$ Para avaliar o funcionamento renal os exames laboratoriais mais solicitados pelos nefrologistas, são através da medida da taxa de filtração glomerular (TFG), principalmente com a dosagem de creatinina sérica. Os exames que avaliam as funções tubulares são menos comumente solicitados. Assim, como a dosagem de alguns marcadores, são exemplos a inulina, uréia, albumina, e cistatina C. ${ }^{3}$ É importante o diagnóstico precoce para o tratamento das doenças renais, além de prevenir futuras doenças secundárias como Hipertensão Arterial Sistêmica e Diabetes Mellitus tipo II. Ademais, resulta em potenciais benefícios para qualidade de vida, longevidade e redução de custos associados ao cuidado em saúde. O agravamento das nefropatias pode levar ao tratamento de diálise e necessidade de um transplante renal. ${ }^{4}$

Segundo a Sociedade Brasileira de Nefrologia (SBN), assim como outras especialidades médicas o cenário brasileiro nesta área se encontra com recursos limitados. Consequentemente um dos principais problemas, é demanda crescente pelo tratamento dialítico enquanto o número de unidades de diálise não aumenta o equivalente, resultando uma superlotação. Gerando assim, um problema de saúde pública. $^{5} \mathrm{O}$ objetivo deste estudo consiste em um levantamento bibliográfico sistemático no qual avalia a importância dos principais biomarcadores renais, para fins 
de um diagnóstico clínico e monitorização do paciente por exames laboratoriais. E assim, contribuir, melhorando a qualidade de vida do mesmo.

\section{DISCUSSÃO}

Na prática laboratorial, os marcadores renais ganham destaque por possibilitarem um diagnóstico precoce de disfunções renais permitindo, desta forma, intervenções terapêuticas e melhora na qualidade de vida do indivíduo acometido antes da evolução da doença renal. ${ }^{6} \mathrm{~A}$ avaliação da função renal pode ser realizada de várias formas, porém, a excreção é a mais utilizada na prática clínica. Visto isso, a Taxa de Filtração Glomerular (TFG) é o método mais indicado, é definida como a medida da depuração de uma substância que é filtrada livremente pelos glomérulos e não sofre reabsorção ou secreção tubular. É igual à soma da taxa de filtração de todos os néfrons funcionantes. A diminuição no funcionamento da TFG pode indicar dano renal, podendo ser de forma fisiológica, uso de drogas, perda de massa renal, ou de néfrons. Neste último, o rim se adapta por um mecanismo fisiológico, em que, os nefróns funcionantes trabalham de forma compensatória suprindo os demais, logo a TFG com valores normais não significa funcionamento normal. ${ }^{1,7,8,9}$ É estimada pelo " clearance" urinário de um marcador ideal de filtração, pois não há possibilidade de ser medida diretamente. $O$ " clearance" é definido como o volume de plasma no qual uma determinada quantidade de substância é removida da urina por unidade de tempo. Essas substâncias são marcadores exógenos tais como inulina, iohexol, iotalamato e o radiofármaco Ácido 99Tcm-Dietilenotriaminopentacético. E marcadores endógenos como a creatinina. Eles poderão ser avaliados através da dosagem sanguínea ou urinária, sendo que alguns deles podem ser dosados das duas formas. $6,7,8,9,10$

\section{MARCADORES POR DOSAGEM SANGUÍNEA}

\section{INULINA}

A inulina é um polímero de frutose com peso molecular de aproximadamente 5.000 Da. É considerada padrão ouro de medida da TFG, apresenta características de um marcador ideal, pois não se liga às proteínas plasmáticas. É livremente filtrada pelos 
glomérulos, não sofre reabsorção, nem secreção pela célula tubular renal e apresentase fisiologicamente inerte, sendo assim, considerada um marcador exógeno da TFG. Porém, esse método possui alto custo, é invasivo com infusão endovenosa contínua e muito complexo, e pode levar a reações de hipersensibilidades. Dessa forma, seu uso é limitado à pesquisa experimental. Como alternativa, tem sido preferível o uso de radiofármacos para poder simplificar os exames laboratoriais nesta área. ${ }^{10}$

\section{IOHEXOL}

O iohexol é um contraste radiológico, não-iônico, hidrossolúvel, de baixa osmolaridade, seguro e com baixa toxicidade. É um marcador exógeno da TFG, sendo eliminado exclusivamente por filtração glomerular, sem sofrer reabsorção e nem secreção, ou seja, pode ser medido o ritmo de depuração renal. . $^{911}$ É apresentado como uma alternativa à depuração de inulina, não necessitando de coleta urinária e infusão endovenosa contínua, podendo ser realizado o exame com apenas uma injeção. O iohexol pode causar eventos de hipersensibilidade, alertamos o paciente a esta possibilidade. Sua técnica deve ser realizada com um suporte de emergência próximo, para um eventual caso alérgico. $\mathrm{O}$ alto custo e a complexidade são fatores que dificultam seu uso na rotina prática laboratorial. ${ }^{9,11}$

\section{IODOTALAMATO (125I-IODOTALAMATO)}

O 125I-iodotalamato é um contraste radiológico iônico. Assim como o iohexol, é filtrado pelo glomérulo renal, não sofrendo reabsorção, nem secreção, sendo assim um marcador exógeno da função da TFG. Por ser um contraste, pode causar, também, eventos de hipersensibilidade. ${ }^{10,11} \mathrm{~A}$ depuração de 125 I-iodotalamato é um exame simples e preciso, realizado com uma única injeção subcutânea. Essa técnica é eficiente, reprodutível, simples e prática, inclusive em crianças saudáveis e em pacientes com doença renal leve ou em estágio avançado. Também possui alto custo e alta complexibilidade. ${ }^{10,11}$ 


\section{ÁCIDO 99TCM-DIETILENOTRIAMINOPENTACÉTICO}

O Ácido dietilenotriaminopentacético (DTPA) possui o quelato 99m Tc-DTPA, que é um radiofármaco, no qual decai por transição isomérica e apresenta baixo peso molecular. É um marcador exógeno da TFG, que tem como vantagem a simplicidade na aplicação e precisão das medidas do seu método, além, de apresentar um menor tempo exposto à radiação. ${ }^{10}$ É eliminado exclusivamente por via renal, porém, pode sofrer uma depuração extra-renal, limitando seu uso como marcador da TFG. Assim como outros radiofármacos $0{ }^{99 m}$ TC-DTPA possui alto custo e prova laboratorial complexa. ${ }^{10,12}$

\section{CREATININA}

A creatinina plasmática provém do catabolismo da creatina muscular. É um metabólito que armazena energia no músculo, na forma de fosfocreatina. A creatina pode ser originada da dieta ou sintetizada endogenamente no fígado, rim e pâncreas, após sintetizada é transportada para as células musculares e cérebro, onde é fosforilada a creatina-fosfato. De forma espontânea, perde o ácido fosfórico ou água, respectivamente, para formar seu anidrido, a creatinina. Esta conversão é uma reação não enzimática e irreversível que ocorre constantemente. Sua produção e concentração sanguínea varia conforme idade, sexo, estilo de vida, saúde e etnia. O que explica sua ampla faixa de referência (creatinina plasmática 0,6 a 1,3mg/dL). É excretada exclusivamente por via renal, onde não é reabsorvida nem reaproveitada pelo organismo. Assim, os níveis de creatinina plasmáticos refletem a taxa de filtração glomerular de forma que os altos níveis de creatinina indicam uma deficiência no funcionamento renal. ${ }^{10,13} \mathrm{Na}$ prática laboratorial sua dosagem é o método mais utilizado para avaliação da função renal. É realizada através do método de Jaffé, onde ocorre uma reação entre a creatinina com a substância picrato alcalino, formando cromógeno de cor vermelha-alaranjada (complexo de Janovski). Esta reação está sujeita a interferentes presentes no sangue, tais como ácido ascórbico, glicose, piruvato, acetona, proteínas, ácido acetoacético, ácido úrico e antibióticos como as cefalosporinas. Além destes interferentes, a dosagem de creatinina possui baixa sensibilidade, a função renal pode ser alterada e só após aproximadamente $50 \%$ de 
perda de funcionalidade é notável alteração dos valores séricos, inviabilizando um diagnóstico precoce..$^{10,13}$

\section{FÓRMULAS MATEMÁTICAS PARA ESTIMATIVA DA TFG}

A Fundação Nacional do Rim (National Kidney Foundation) recomenda fórmulas matemáticas para calcular uma melhor estimativa da TFG. Na rotina laboratorial as equações mais utilizadas são as de Cockcroft-Gault que calcula o clearence de creatinina por uma fórmula que utiliza creatinina sérica, idade, peso e sexo. A fórmula de Modificação Dietética na Doença Renal (MDRD) na qual faz uma estimativa da TFG com base em idade, etnia, sexo e creatinina sérica. ${ }^{10,13} \mathrm{O}$ grupo Chronic Kidney Disease Epidemiology Collaboration (CKD-EPI) desenvolveu uma nova equação mais recentemente, sendo uma variação da fórmula do MDRD. Foi recomendado na nova versão das Diretrizes para Avaliação e Manuseio da Doença Renal Crônica (DRC) na Prática Clínica (Kidney Disease Improvement Global Outcomes - KDIGO), publicada no início de 2013, a utilização da equação CKD-EPI para a estimativa da TFG. Na sequência iremos ilustrar estas equações (Tabela 1). ${ }^{10,13}$

Tabela 1 - Fórmulas para estimativa da taxa de filtração glomerular (TFG) com base na creatinina sérica. ${ }^{13}$

\begin{tabular}{|c|c|}
\hline Método & Estimativa da taxa de filtração glomerular/CICr \\
\hline $\begin{array}{l}\text { Cockcroft- } \\
\text { Gault }\end{array}$ & $\begin{array}{l}{[140 \text { - idade (anos) ] x peso (x 0,85 se mulher) / ( } 72 \times \text { creatinina sérica }} \\
\mathrm{mg} / \mathrm{dL})\end{array}$ \\
\hline MDRD & $\begin{array}{l}186 \times(\text { creatinina sérica })^{-1,154} \times(\text { idade })-0,203 \times(0,742 \text { se mulher }) \times \\
(1,212 \text { negros })\end{array}$ \\
\hline CKD-EPI & 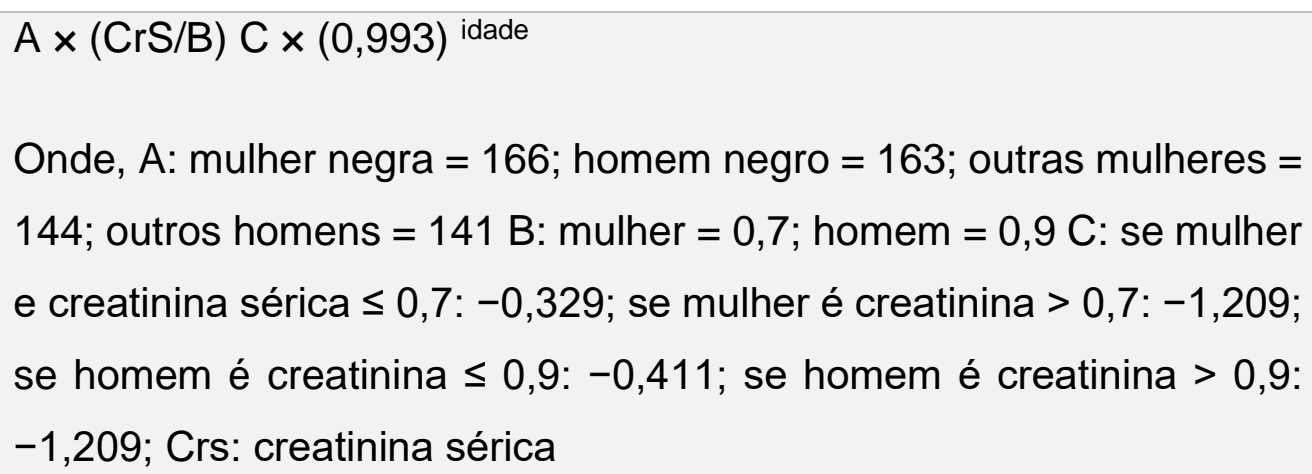 \\
\hline
\end{tabular}




\section{URÉIA}

A uréia é proveniente do catabolismo de aminoácidos de proteínas da alimentação, que originam amônia na qual, posteriormente, se converte em uréia $\left(\mathrm{NH}_{2}-\mathrm{CO}-\mathrm{NH}_{2}\right)$ no fígado associado ao $\mathrm{CO}_{2}$. Ela constitui $45 \%$ do nitrogênio não protéico no sangue. Sua eliminação é realizada com seu transporte pelo plasma até os rins, onde é filtrada pelos glomérulos e posteriormente excretada na urina. Porém, nos túbulos renais ela é reabsorvida de $40-70 \%$, levando a um maior retorno de ureia ainda nos túbulos renais e a uma subestimação da filtração glomerular calculada pelo clearence de ureia. Ela também é eliminada através do trato gastrintestinal e da pele. ${ }^{14}$ Uma disfunção renal pode levar a alteração nos valores séricos de uréia. Outros fatores como, a taxa de produção hepática, trauma, insuficiência cardíaca congestiva, infecção, depleção de sódio e uso de corticosteroides, diuréticos ou tetraciclinas, conteúdo proteico da dieta, teor do catabolismo proteico, estado de hidratação do paciente e presença de sangramento intestinal, agem como interferentes nesta dosagem laboratorial. Entretanto, apesar destas limitações a dosagem de ureia é utilizada como biomarcador para o dano renal. Principalmente em combinação com a dosagem de creatinina, essa relação pode ser útil em pacientes com quedas significantes na taxa de filtração glomerular (TFG), podendo apresentar-se alterada em estados patológicos diferentes. ${ }^{10,14}$ Os métodos enzimáticos colorimétricos são os mais utilizados para esta dosagem. Onde a uréia é hidrolisada pela enzima urease formando íons amônio e $\mathrm{CO}_{2}$, seguida de uma quantificação. É nessa fase que há o monitoramento da variação cromática para a determinação dos valores de uréia. Os métodos de química seca também têm sido descritos utilizando a urease. De modo geral, estes métodos não sofrem interferências analíticas. ${ }^{10,14}$

\section{CISTATINA C}

A cistatina $C$ é uma potente inibidora de proteases pertencente à família das cistatinas, possui baixo peso molecular (aproximadamente 13,3 kDa), alto ponto isoelétrico e não glicosada. É produzida continuadamente por todas as células nucleadas e está presente no organismo, nos fluidos biológicos como o soro, líquido seminal e 
cefalorraquidiano. ${ }^{15,16}$ Este marcador é metabolizado e reabsorvida no túbulo renal proximal, não havendo secreção renal, nem extra-renal. Sua determinação sérica reflete diretamente em um estado de injuria renal aguda, assim por conta da lesão ela não é metabolizada e nem reabsorvida, havendo níveis significativos desta proteína no soro e na urina, sendo caracterizada como uma proteína de função renal aguda. Logo, sua concentração depende da TFG, não sendo afetada por interferentes como dieta, estado nutricional, inflamação ou doenças malignas, e também não existe variação significativa entre sexo já que não depende de massa muscular. Diferente da creatinina, a cistatina $C$ é produzida constantemente em vários tecidos do organismo. Outra vantagem em relação a creatinina e outras proteínas de baixo peso molecular é a menor variabilidade nas determinações sanguíneas, sua meia-vida mais curta e o seu menor volume de distribuição tornam a cistatina $C$ um marcador de função glomerular com maior sensibilidade para detectar diminuições leves da TFG na Doença Renal Crônica (DRC). Na pratica laboratorial sua dosagem pode ser realizada em soro ou plasma, nas mesmas condições de coleta da creatinina. ${ }^{1,17}$ Alguns estudos demonstraram que a cistatina $C$ tem grande potencial para substituir a creatinina sérica. Outros estudos ainda têm sugerido que a cistatina $C$ é superior à $D E C$, quando uma disfunção renal subclínica está presente, possibilitando a detecção precoce do declínio da função renal, uma grande vantagem para não levar a DRC. ${ }^{10}$

\section{MARCADORES URINÁRIOS}

\section{PROTEINÚRIA}

É uma condição clínica na qual é encontrada quantidade anormal de proteína na urina. A faixa de referência de proteína total excretada na urina varia de $20 \mathrm{mg}$ a $150 \mathrm{mg} / \mathrm{dia}$, onde metade é albumina e o restante quase totalmente à proteína de Tamm-Horsfall (um constituinte dos cilindros urinários). ${ }^{10} \mathrm{~A}$ proteinúria pode ser advinda de várias origens, são elas: glomerular, tubular, sobrecarga e pós-renal. A mais comum é a glomerular onde ocorre perda da albumina e proteínas de peso parecido, como a antitrombina, transferrina, pré-albumina, a1-glicoproteína ácida e alpha-1-antitripsina, se piorar a lesão ainda podem ser perdidas proteínas maiores, como a alpha-2- 
macroglobulina e a lipoproteína $b$. A proteinúria de origem tubular ocorre perda de proteínas de baixo peso molecular, uma vez que estas são livremente filtradas pelos glomérulos, mas não são reabsorvidas nos túbulos proximais. Em relação as de sobrecarga, observa-se extravasamento de uma proteína normal de baixo peso molecular do plasma para a urina, como hemoglobina, mioglobina e proteína de Bence-Jones. Já na pós-renal, há produção de proteínas pelas vias urinárias inferiores devido à inflamação ou malignidade. ${ }^{10,16}$ No laboratório clínico, as dosagens dessas proteínas na urina são realizadas através dos métodos quantitativos colorimétricos utilizando azul de Coomassie, Ponceau S, cloridrato de benzentônio e molibdato de pirogalol vermelho. O método proteínas totais/creatinina tem sido mais recomendada por estar menos sujeito a erros de coleta. Sua faixa de referência vai depender da amostra utilizada ( $<300 \mathrm{mg} / 24$ horas ou $<200 \mathrm{mg} / \mathrm{g}$ de creatinina). Também é utilizado fita reagente, no entanto estas fitas são especificas para albumina e não de proteínas totais, podendo ser um viés na análise. Outras situações que podem levar a interferentes, é se a urina estiver muito alcalina ou contaminada com amônia quaternária, clorexidina e corrimento vaginal. Sendo assim, é necessário a análise quantitativa de proteínas na urina em pacientes que apresentem fita reagente positiva em amostra isolada, para evitar falsos positivos. ${ }^{10}$

\section{ALBUMINÚRIA}

A albuminúria ou microalbuminúria consiste em uma quantidade anormal de albumina encontrada na urina, significando um dano renal. A albumina é a proteína em maior concentração no plasma, ela é sintetizada no fígado. ${ }^{10,18}$ Fisiopatologicamente, a albuminúria é explicada por um evento inflamatório sistêmico, podendo levar a uma disfunção endotelial e um consequente aumento da permeabilidade capilar. De forma fisiológica, exercícios físicos intensos e desidratação causam um aumento da albumina plasmática, enquanto dano hepático, déficit alimentar, síndrome de má absorção, parasitismo e hemorragias, causam redução nos níveis plasmáticos. Nas doenças renais, as lesões glomerulares e tubulares, causam aumento da filtração das proteínas plasmáticas e redução da reabsorção das mesmas, levando à hipoalbuminemia Estudos demonstraram uma correlação entre albuminúria e o 
desenvolvimento da Doença Renal Crônica (DRC) e recomendações posteriores a essas diretrizes estabelecem a classificação da doença renal por nível de albuminúria e TFG. ${ }^{10,18}$ Para a sua dosagem os métodos mais utilizados são de nefelometria e turbidimetria. Entretanto, podem subestimar os valores reais, sendo a cromatografia líquida de alta performance a maneira mais eficaz. ${ }^{10,18}$

\section{MOLÉCULA DE INJÚRIA RENAL 1 (KIM - 1)}

A molécula de injúria renal 1 chamada de KIM-1 em humanos, é uma glicoproteína transmembrana, de com peso molecular de aproximadamente $90 \mathrm{kDa}$, com um domínio externo clivável, localizado na membrana apical de túbulos com lesão aguda e crônica. É um biomarcador do túbulo proximal, se apresenta quando existe algum dano renal e é relacionada principalmente a Insuficiência Renal Aguda (IRA), mas também se apresenta em várias patologias renais, como nefropatia diabética, glomeruloesclerose focal, nefropatia IgA, rejeição ao enxerto, entre outras. Acreditase ainda que $\mathrm{KIM}-1$, exerça um papel importante na capacidade de reparo e regeneração dos túbulos renais. Algumas agências regulatórias para área de saúde como norte-americana e europeia, reconhecem este biomarcador como específico e altamente sensível para monitorar doença renal que foi induzida por medicamentos. ${ }^{3,18,19}$ Sua capacidade de inserção na membrana apical do túbulo proximal no dano renal, e sua expressão presente de forma persistente até a recuperação destas células tubulares, a torna um importante biomarcador renal. A KIM-1 age na resposta imune da IRA, sendo liberada na urina e assim detectada. Sua dosagem é reprodutível, fácil e rápida, com potencial aplicação na clínica, porém, mais estudos se faz necessário. ${ }^{19,20}$

\section{INTERLEUCINA-18}

A Interleucina-18 (IL-18) é uma citocina pró-inflamatória da família das citocinas IL-1, apresenta baixo peso molecular $(18 \mathrm{kDa})$, constitutivamente expressa no néfron distal (em nefropatias) é utilizada como biomarcador precoce para lesão renal aguda. É secretada através de células do sistema imune e tecidos extra renais e, em condições como sepse, traumas, após grandes cirurgias, doenças autoimunes e inflamatórias, o 
que limita a sensibilidade e à especificidade dessa citocina como biomarcador de IRA. ${ }^{10,20,21}$ Alguns estudos demonstraram essa vantagem da IL-18 aparecer precocemente melhorando o prognóstico do paciente, por exemplo, um estudo onde pacientes que fizeram cirurgia cardiopulmonar/by-pass e desenvolveram Insuficiência Renal Aguda (IRA) tiveram seus níveis de IL-18 aumentados após 6 horas da cirurgia. Em outro caso ela também se demonstra como um ótimo biomarcador para pacientes com síndrome nefrótica. Em comparação com outros marcadores da lesão renal a IL18, bem como a KIM-1, amostrou-se especifica para o túbulo proximal e na lesão de isquemia-reperfusão renal. ${ }^{10,21}$ Por se tratar de uma molécula inflamatória a IL-18 é liberada pelos macrófagos em resposta a alguma inflamação podendo ser um interferente ocasionando uma desvantagem no seu uso, consequentemente limitando sua aplicação. ${ }^{20}$

\section{DISMORFISMO ERITROCITÁRIO}

Condição clínica que consiste em uma modificação morfológica de eritrócitos detectados na urina. Na hematúria ocorre a presença de sangue na urina, ou seja, eritrócitos na urina, no dismorfismo esses eritrócitos estão alterados morfologicamente devido algum problema renal, podendo ser glomerular, ou extraglomerular como no túbulo proximal, ducto coletor e demais trato urinário. O dismorfismo auxilia na detecção da origem do sangramento indicando no aparelho renal, onde poderá existir uma lesão. ${ }^{10}$ Para diferenciar a hematúria glomerular da extraglomerular a microscopia de contraste de fase vem sendo muito útil. Na glomerular as hemácias são dismórficas por conta da alteração morfológica que sofrem ao passar pela membrana glomerular lesada, podendo aparecer nas formas de esquizócitos, anulócitos, equinócitos, estomatócitos, codócitos, acantócitos, dentre outras. Já na extraglomerular as hemácias estão isomórficas como na forma sanguínea. ${ }^{10,22}$ Além da alteração ao passar pela membrana glomerular, o dismorfismo pode ser caracterizada por várias condições como alterações contínuas na pressão osmótica, alteração no pH tubular, destruição enzimática do glicocálix, de células tubulares epiteliais que leva à degradação de proteínas de superfície renal, perda de proteínas do citoesqueleto da membrana, e hemólise. Alguns autores também relatam a 
hipocromasia. ${ }^{10,22} \mathrm{~A}$ análise laboratorial deste biomarcador é feita de forma não invasiva através da urina. Essa urina é coletada e, posteriormente, centrifugada para então ser analisado o sedimento urinário por microscopia. $O$ analista será importante nesta fase, o que deixa a análise subjetiva. $O$ exame é de baixa complexidade e baixo custo. ${ }^{10,22}$

\section{LIPOCALINA ASSOCIADA À GELATINASE DE NEUTRÓFILOS (NGAL)}

A lipocalina associada à gelatinase de neutrófilos (neutrophil gelatinase-associated lipocalin - NGAL), é uma molécula proteica de peso molecular aproximado de $25 \mathrm{kDa}$, possui 178 aminoácidos. Está presente em células epiteliais do túbulo proximal e grânulos de neutrófilos humanos, também podem estar presentes em células tumorais. Seu principal ligante é o grupo sideróforo, um composto orgânico produzido por bactérias, plantas e provavelmente em mamíferos, responsável pelo fornecimento de ferro. Fisiologicamente protege o rim na lesão das células tubulares onde diminui a apoptose e aumenta a proliferação dessas células, também contribui para aumentar a captação de ferro e regular a síntese da heme-oxigenase 1. Um estudo mostrou (Dulce, et al., 2016) que em situação homeostática existe uma pequena secreção de NGAL, já após algum distúrbio renal (como injúria renal aguda (IRA), nefropatia diabética (ND), nefropatia mediada por $\lg A(N \lg A)$ e nefrite lúpica) seus níveis se elevaram poucas horas depois, sendo um bom marcador precoce no diagnóstico. É proposto que esse aumento pode ser pelos processos de bacteriostase e proliferação de túbulos renais, que constituem possíveis vias para a proteção feita pelo NGAL ao tecido renal. Seus níveis elevados também podem surgir em outras doenças como tumor cerebral, doença inflamatória do intestino e pré-eclâmpsia. ${ }^{3,10,23} \mathrm{O}$ diagnóstico laboratorial pode ser realizado através da urina e do plasma. A concentração plasmática da NGAL inclui a produção desta proteína em outros órgãos distintos dos rins, enquanto que a dosagem urinária reflete com mais fidelidade a produção renal desta proteína. A dosagem urinária possui desvantagem para pacientes com oligúria, devido ao excesso de hidratação, da desidratação e do tratamento diurético. Apesar da NGAL se apresentar como um bom marcador para IRA e outras patologias renais 
mais estudos precisam ser realizados e valores de cut-off mais apropriados para diferentes situações clínicas e populações. ${ }^{10}$

\section{DEPURAÇÃO ENDÓGENA DE CREATININA (DCE)}

A depuração endógena da creatinina (DEC) também conhecido como "clearance" de creatinina, que é realizada com o exame urina de 24 horas, é uma opção mais verdadeira quando comparada aos níveis de creatinina plasmática. Possui como vantagem o baixo custo e acessibilidade em grande parte dos laboratórios, mas apresenta como desvantagens a coleta inadequada da urina e o aumento da secreção tubular de creatinina, que ocorre quando a TFG diminui, levando a uma superestimação do valor desta. Alguns pacientes com doença renal crônica (DRC) avançada podem ter a DEC duas vezes maior que a TFG. Outro fator que pode afetar a acurácia da DEC é o aumento da depuração extra renal da creatinina na DRC avançada. Como resultado, a creatinina sérica diminui, elevando falsamente o valor da DEC. ${ }^{9,10}$

A seguir, está descrito um resumo dos biomarcadores renais (Tabela 2) mencionados nesse estudo de revisão:

Tabela 2 - Principais características dos Biomarcadores Renais

1. Taxa de Filtração Apresenta diretamente, através da depuração de Glomerular (TFG) substâncias, o funcionamento renal, sendo um dos marcadores mais comumente utilizados.

2. Inulina

3. lohexol
É filtrado pelos glomérulos renais livremente, não sofre reabsorção, nem secreção renal. Além de não se ligar a proteínas plasmáticas.

Contraste não-iônico, com características semelhantes a inulina, pode substitui-la pela vantagem da técnica de injeção única. 
4. 125I-Iodotalamato

5. DTPA

6. Creatinina

7. Uréia

8. Cistatina C

9. Proteinúria

10. Albuminúria

11. $\mathrm{KIM}-1$

12. IL -18

13.

Eritrocitário

14. NGAL
Contraste iônico com características semelhantes a inulina, pode substitui-la pela vantagem da técnica de injeção única.

Radiofármaco considerado melhor indicador para avaliar TFG.

É excretada exclusivamente por via renal, onde não é reabsorvida nem reaproveitada pelo organismo.

Sua principal utilidade consiste na relação uréia creatinina.

Caracterizada como uma proteína de função renal aguda

É um marcador onde seu fator de risco é independente da progressão da lesão renal.

Seus níveis podem aumentar proporcional ao dano renal avaliando a progressão.

Há expressão presente quando há um dano nas células tubulares tornando-a um importante biomarcador renal. Utilizado como biomarcador precoce para lesão renal aguda.

O dismorfismo auxilia na detecção da origem do sangramento, indicando assim onde, no aparelho renal, poderá existir uma lesão.

No dano renal tem seus níveis aumentados em poucas horas depois, sendo um bom marcador precoce.

\section{CONSIDERAÇÕES FINAIS}

O presente estudo demonstra que um bom biomarcador deve estar presente logo após um dano renal, apresentando valores seguros da TFG, sem grandes interferentes, e ademais ter baixo custo na prática clínica laboratorial. A TFG possui marcadores exógenos sendo os contrastes radiológicos e a inulina os mais utilizados, porém, possuem um elevado custo e mais estudos são necessários, e marcadores 
exógenos como a dosagem de creatinina que entre todos os estudos se demonstra a mais comumente utilizada na pratica clínica, apesar de todos os seus interferentes. A uréia é mais utilizada quando correlacionada a creatinina. A proteinúria e albuminúria são mais utilizadas quando em conjunto com outros para confirmar o diagnóstico. Os marcadores como NGAL, cistatina C, KIM-1 e IL-18, estão mais ligados ao diagnóstico da IRA. Entretanto está área ainda necessita de mais estudos para comprovação da eficácia e seletividade dos marcadores, para propiciar um diagnóstico mais diferenciado, especifico e seguro, auxiliando na melhor conduta clínica terapêutica.

\section{REFERÊNCIAS}

1. Luis da Silva Nunes G. Measurement of kidney function in patient with hypertension. Rev Bras Hipertens. 2007;14:162-6.

2. Nascimento L, Sousa C, Setembro FS De. Biomarcadores renais e sua importância no diagnóstico de nefropatias. Rev Científica da FASETE 2017;162-76.

3. PERES, Luis Alberto Batista et al. Biomarcadores da injúria renal aguda. J. Bras. Nefrol. 2013; 35:229-236

4. Marinho AWGB, Penha A da P, Silva MT, Galvão TF. Prevalência de doença renal crônica em adultos no Brasil: revisão sistemática da literatura. Cad Saúde Coletiva. $2017 ; 25: 379-88$.

5. Sesso RC, Lopes AA, Thomé FS, Lugon JR, Martins CT. Brazilian chronic dialysis Survey 2016. J Bras Nefrol. 2017;39:261-6

6. Urbschat A, Obermüller N, Haferkamp A. Biomarkers of kidney injury. Biomarkers. 2011;16(SUPPL. 1).

7. Bastos MG, Bregman R, Kirsztajn GM. Doença renal crônica: frequente e grave, mas também prevenível e tratável. Rev Assoc Med Bras. 2010;56:248-53. 
8. Bastos MG, Bregman R, Kirsztajn GM. Chronic kidney disease: importance of early diagnosis, immediate referral and structured interdisciplinary approach to improve outcomes in patients not yet on dialysis. J Bras Nefrol 2011; 33:93-108

9. Renal F. Fisiologia Renal. Fundam da Circ Extracorpórea. 2006; Em vol 1.

10. Dusse L, Rios D, Souza, L. Morais R, Domingueti C, Gomes K. Biomarkers of renal function: what is currently available?. RBAC. 2018; 49:41-51

11. Juchem BC, Dall'Agnol CM. Reações adversas imediatas ao contaste iodado intravenoso em tomografia computadorizada. Rev Latino-Am Enferm. 2007;15:78-83.

12. Manuel RF. Taxa de filtração glomerular pelo EDTA marcado com 51 cromo e com índio em equinos. Arq. Bras. Med. Vet. Zootec. 2009; 61:547-52.

13. Nunes E. Terapia antirretroviral e função renal. Braz J Infect Dis.2016;(2):82-90

14. Motta VT. Bioquímica Clínica: Princípios e Interpretações. Em Vol 15: Nitrogênio não-protéico. São Paulo: Medbook; 2009. p. 233-246.

15. Lakshmanan S, Kumar S, Singh RBS. Urinary Cystatin C as an Early Biomarker of Acute Kidney Injury in Authors. JMSCR. 2018;06: 991-7.

16. Nishida SK, Mastroianni G. 2011. Serum cystatin C: a practical alternative for renal function. J Bras Nefrol. 2011;3:261-7

17. Abensur H.Biomarcadores na nefrologia. $1^{\circ}$ Ed. São Paulo: São Paulo; 2011.

18. Zanella MT. Microalbuminúria: fator de risco cardiovascular e renal subestimado na prática clínica. Arq Bras Endocrinol Metabol. 2006;50(2):313-21.

19. Carmo LP de F do. Avaliação da performance dos biomarcadores e da bioquímica urinária no diagnóstico de injúria renal aguda em pacientes críticos: coorte prospectiva. [tese]. São Paulo (SP): Faculdade de Medicina da Universidade de São Paulo; 2016. 
20. De D, Integrado M, Medicina E, De A, Bibliográfica $R$, Filipa $H$, et al. Novos marcadores de lesão renal aguda. [dissertação]. Porto (PO). Instituto de Ciências Biomédicas Abel Salazar; 2011.

21. Revisão ADE, Oliveira TL, Figueredo CM. IL-18 and its importance for the Chronic inflammation diseases. Rev. de Ciências Médicas e Biológicas .2010; 9(2):150-6.

22. Kirsztajn GM. 2009. Evaluation of Renal Function. J Bras Nefrol. 2009;31:14-20.

23. Wagner LAGO M, Noal MORESCO R, Vargas BOCHI G. Neutrophil gelatinaseassociated lipocalin (NGAL) as a biomarker of kidney damage: a review. Rev Inst Adolfo Lutz. 2016; 1-13.

Enviado: Março, 2019.

Aprovado: Julho, 2019. 